\title{
Calculation of Effective Structural Number Using Simple Neural Network for Some Road Links in Indonesia
}

\author{
Siegfried \\ Puslitbang Jalan dan Jembatan \\ Jl. AH Nasution 264, Bandung \\ syafier@gmail.com
}

\begin{abstract}
In the pavement maintenance system, the parameter of effective structural number (SNeff) would be a considered factor in deciding whether a road link would be repaired or not. To calculate this parameter, it is required the testing of Falling Weight Deflectometer (FWD) and information of layer composition and thicknesses. The combination of these information and using the method of AASHTO'93, it can be calculated the SNeff. These two information generally would be gained through the testings of core drill and test pit which would take time and cost. To overcome these problems, the neural network method or precisely the artificial neural network is developed for analysis of pavement structure. From the analysis, it can be said that the neural network of single perceptron can be used for predicting the SNeff with an acceptable error. In general the value of SNeff obtained from neural network calculation is lower than that of AASHTO'93. In this paper it is also recommended to develop the neural network using multi layer perceptron for the use on pavement system analysis that might be decreasing the error.
\end{abstract}

Keywords-neural network; SNeff; FWD

\section{INTRODUCTION}

In pavement management system, it needs a data collection of road structural strength which is manifested by the value of Effective Structural Number (SNeff). The SNeff is parameter required to decide whether a pavement requires an overlay to accommodate the predicted traffic for a certain service life. Deflection which is obtained by Falling Weight Deflectometer (FWD) is a parameter to deal with the calculation of SNeff. Because of the FWD has several sensors, generally the deflection data is expressed as deflection bowl. There are some methods available to calculate the SNeff such as AASHTO'93, Austroad, etc.

In calculating SNeff, besides the deflection bowl, it also needs the thickness of each layer of pavement system. The thickness information is obtained through Non Destructive Test as well as Destructive Test. The Non Destructive Test is namely Ground Penetration Radar (GPR) and Spectral Analysis Surface Wave (SASW). While the Destructive Test is such as through core drill or test pit.

Because of high volume traffic, it may be rather impossible to have a destructive test for a road link being analyzed. It is quite expensive and also time consuming. To overcome this problem, some highway engineers suggested to use Neural Networks method to deal with the deflection data only in calculating the value of SNeff.

In dealing with the Neural Networks method, the deflection obtained from FWD testing is converted into basin parameter such as Area, Area Under Pavement Profile, Area Index, Base Curvature Index, Base Damage Index, and Deflection Ratio [5] Some basin parameter has a good correlation to a certain pavement parameter.

The neural networks method used in this paper is a simple one which means the system has one layer perceptron. The layer is just functioned to accommodate input and output for the system. The function chosen is a sigmoid which is usually used in neural networks application.

Basic philosophy of neural networks method is based on the mechanism of neuron in receiving signals and deciding the best solutions. In biological system, the information obtained is processed by neuron and then deciding the solution. While for the artificial neural net, the process is modelled by the transfer function of sigmoid type. This process is repeated many times until it gets the best solution which is still under the allowable error. Neural networks can be used effectively for the identification and control of dynamical systems, mapping the input-output representation of an unknown system [2].

Using neural network method, it is required training data to teach the system in simulation the best solution. The training data collected in this paper is obtained through simulation using Ken Pave program. There are 42 data that consist of deflection in the same position as FWD geophones. The variations of physical simulated pavement are modulus and thhicknesses of each layer.

In this paper the neural networks is aimed to calculate effective structural number (SNeff) of some road links in Indonesia i.e. Jatibarang, Padalarang-Purwakarta, and Jln. Sukarno-Hatta Bandung. The SNeff calculated is then compared to that of using AASHTO'93 method. It is then obtained that the SNeff calculated by neural network is a bit less than that of AASHTO'93. 


\section{A. Simple Neural Network}

At the moment artificial neural network is also developed to solve engineering problems. This method is based on the mechanism of a neuron in receiving signals and deciding the best solution. The computer is used to imitate the way of human thinking in solving problems by modelling the activities in biological neuron.

An artificial network method is programmed to have a certain output. All of outputs and conclusions are based on the system experiences in training process. During the training process, many patterns of input-output relationship are introduced to the system, and the network would find the best solution [3].

The simple neural network method used in this paper consists of one single layer perceptron which just have one layer of input and output as shown in Figure 1.

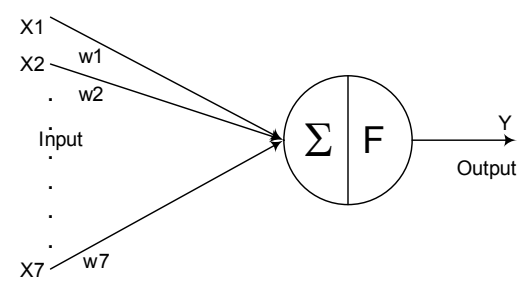

Figure 1. One single layer perceptron

As illustrated in Figure 1, input of the system is $x$ and then multiplied by Weight $\mathrm{w}$. The multiplication of $\mathrm{x}$ and $\mathrm{w}$ then is summed and again multiplied by activation function $\mathrm{F}$ to obtain the output Y.

There are several types of activation function available. One of very common function in neural network is then called Sigmoid function as written in Equation (1) and illustrated in Figure 2.

$$
f(x)=\frac{1}{1+e^{x}}
$$

\section{Where :}

$\mathrm{f}(\mathrm{x})=$ activation function.

$\mathrm{X}=$ input variable.

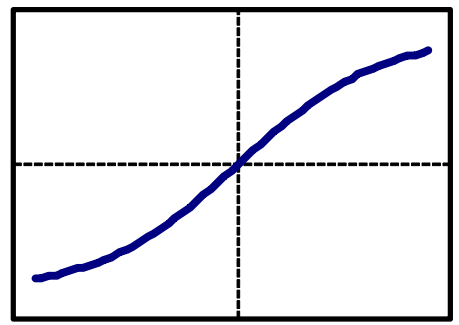

Figure 2. Sigmoid function
If the output $\mathrm{Y}$ is not as same as desired value, it then carries out a back propagation that is used to make a correction of weight value [4]. The new weight is then used to do the same calculation. This is done repeatedly until it gets the allowable error. The error value usually is limited in the Root Mean Square (RMS) as follows:

$$
\text { RMS }=\frac{1}{N} \sqrt{\frac{d^{2}-Y^{2}}{d^{2}}}
$$

Where:

RMS $=$ Root mean square (\%)

$\mathrm{N}=$ Number of data

$\mathrm{d}=$ Desired value

$\mathrm{Y}=$ Output.

\section{B. Falling Weight Deflectometer (FWD)}

The Falling Weight Deflectometer (FWD) is a equipment purposing to collect deflection data of a pavement structure. Data collected is in the form of deflection bowl that is usually for both calculation the strength of a pavement structure in the term of Structural Number (SN) value and modulus of each layer. The SN value is also used for calculation of the overlay needed to accommodate traffic passed during its service life. A schematic of FWD equipment is shown in Figure 3.

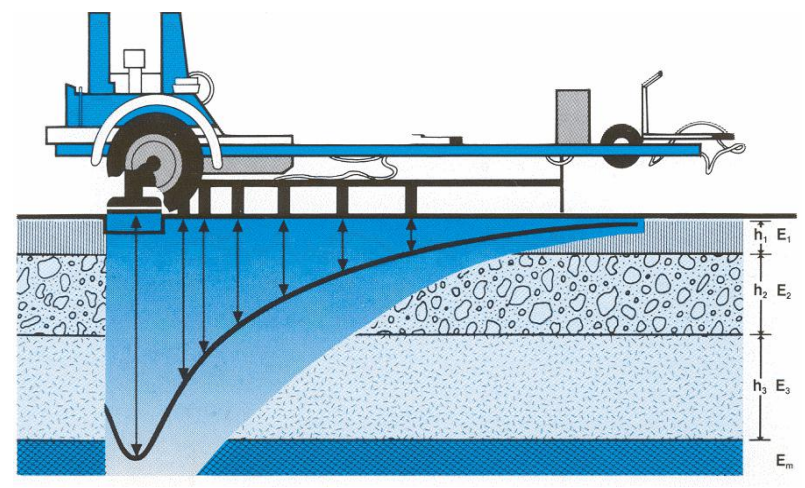

Figure 3. Schematic of a FWD system

As shown in Figure 3, there are 7 geophones available in a unit of FWD. Each geophone would record the deflection value generated at a certain distance from the load applied.

\section{SNeff Using AASHTO'93 Method}

In AASHTO'93 the SNeff is calculated using the following formula [1]:

$$
\text { SNeff }=0.0045 \mathrm{D} \sqrt[3]{E p}
$$

Where :

SNeff= effective structural number existing pavement(in). $\mathrm{D}=$ the total thickness of pavement above sub grade (in). $\mathrm{Ep}=$ pavement modulus (psi).

While to get the pavement modulus is used equation (4). 


$$
d 0=1.5 p a\left\{\frac{1}{M r \sqrt{1+\left(\frac{D^{3}}{a} \sqrt{\frac{E p}{M r}}\right)^{2}}}+\frac{\left[1-\frac{1}{\sqrt{1+\left(\frac{D}{a}\right)^{2}}}\right]}{E p}\right\}
$$

Where:

do $=$ Deflection at the centre of load (in).

$\mathrm{p}=$ The applied stress (psi)

$\mathrm{a}=$ Radius of plate (inci).

$\mathrm{Mr}=$ Subgrade resilient modulus (psi).

\section{Training Data}

In dealing with neural network method, it needs a series of training data. The data group is then informed to the system to find a best solution for the problem.

In this paper the training data is generated using Ken Pave program, The pavement is modelled into 3 layers. Afterward, the deflection is calculated in the same distance as that of the FWD's geophone location. It is then taken the standard load of $580 \mathrm{kPa}$. The structural number is then calculated through Equation (5).

$$
S N=a 1 D 1+a 2 D 2+a 3 D 3
$$

Where :

$\mathrm{SN}=$ Structural number $(\mathrm{cm})$.

ai = layer coefficient of $i$-th.

di $=$ thickness i-th layer. $(\mathrm{cm})$.

To obtain the value of a of each type of layer is used the graphs and equations in the AASHTO'1993. The deflection data is then converted into basin parameter such as Area, Area Under Pavement Profile, Area Index, Base Curvature Index, Base Damage Index, and Deflection Ratio [5].

After calculation of each data, it is then made a curve of the training data and calculated value as shown in Figure 4. From Figure 4, it can be said that the training is finished after the error gets value of $5.50 \%$. The Epoch value (number of presentation all data) is 524,943 . It means that in order to get the best solution the computer has done 524,943 times of calculation. From this fact, it is recommended to use a unit of computer in dealing with neural network method.

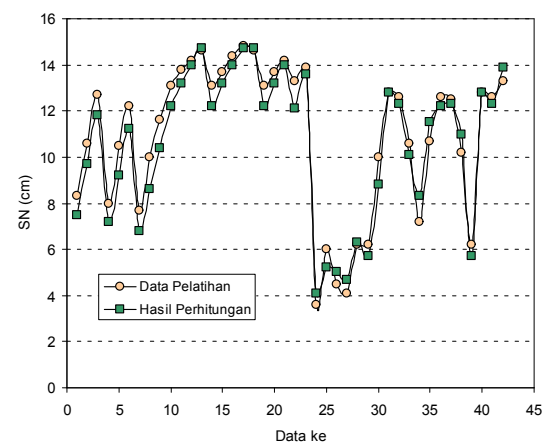

Figure 4. Training data vs Output

\section{RESULTS AND DISCUSSION}

The calculation of SNeff is carried out using AASHTO'93 and neural network method. Data required in dealing with the AASHTO'93 is deflection data and thicknesses of each layer of pavement. While for dealing with neural net work the data required is only deflection values by FWD. For location of Jatibarang the results of SNeff are shown in Table 1 and illustrated in Figure 5.

From Table 1 and Figure 5, it can be said that the calculation of SNeff using the Neural Network is nearly similar to that of AASHTO'93 with error $8.5 \%$ to $12.9 \%$. The average value of $\mathrm{SN}$ at this area is $10.8 \%$.

Table 1. Results of Jatibarang location

\begin{tabular}{|c|c|c|c|}
\hline \multirow{2}{*}{ Data ke } & \multicolumn{2}{|c|}{ SN (cm) } & \multirow{2}{*}{ \% error } \\
\cline { 2 - 3 } & AASHTO'93 & Neural Net & \\
\hline 1 & 28 & 24.8 & 12.9 \\
\hline 2 & 27 & 24.1 & 12.0 \\
\hline 3 & 27 & 24.5 & 10.2 \\
\hline 4 & 27 & 24.4 & 10.7 \\
\hline 5 & 28 & 25.2 & 11.1 \\
\hline 6 & 28 & 25.8 & 8.5 \\
\hline 7 & 29 & 26.0 & 11.5 \\
\hline 8 & 29 & 26.4 & 9.8 \\
\hline 9 & 27 & 24.2 & 11.6 \\
\hline 10 & 27 & 24.7 & 9.3 \\
\hline Rata-rata= & 27.7 & 25.0 & 10.8 \\
\hline
\end{tabular}

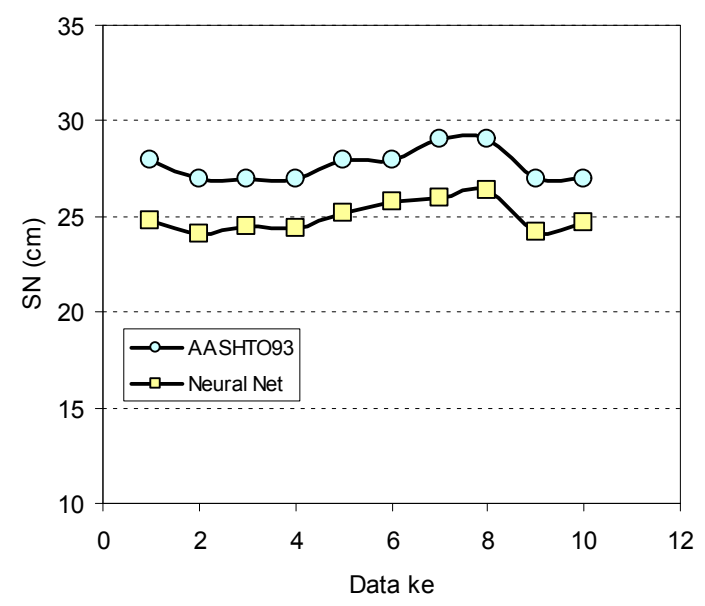

Figure 5. SNeff at location Jatibarang

From Figure 6 it can be seen that the trend of both results seems quite same eventhough the results of neural net calculation is a bit lower. This fact will give a statement that the neural network method can be used to calculate the effective structural number (SNeff).

The calculation for location Purwakarta-Padalarang is shown in Table 2 and illustrated in Figure 6. 
Table 2. Results of Padalarang - Purwakarta

\begin{tabular}{|c|c|c|c|}
\hline \multirow{2}{*}{ Data ke } & \multicolumn{2}{|c|}{ SN (cm) } & \multirow{2}{*}{$\%$ error } \\
\cline { 2 - 3 } & AASHTO'93 & Neural Net & \\
\hline 1 & 17.6 & 16.4 & 7.3 \\
\hline 2 & 17.1 & 16.0 & 6.9 \\
\hline 3 & 18.5 & 18.9 & 2.1 \\
\hline 4 & 20.1 & 19.2 & 4.7 \\
\hline 5 & 16.7 & 16.2 & 3.1 \\
\hline 6 & 13.0 & 14.8 & 12.2 \\
\hline 7 & 17.0 & 16.2 & 4.9 \\
\hline 8 & 13.2 & 13.2 & 0.0 \\
\hline 9 & 17.6 & 15.3 & 15.0 \\
\hline 10 & 14.9 & 15.8 & 5.7 \\
\hline Rata-rata= & 16.6 & 16 & 2.3 \\
\hline
\end{tabular}

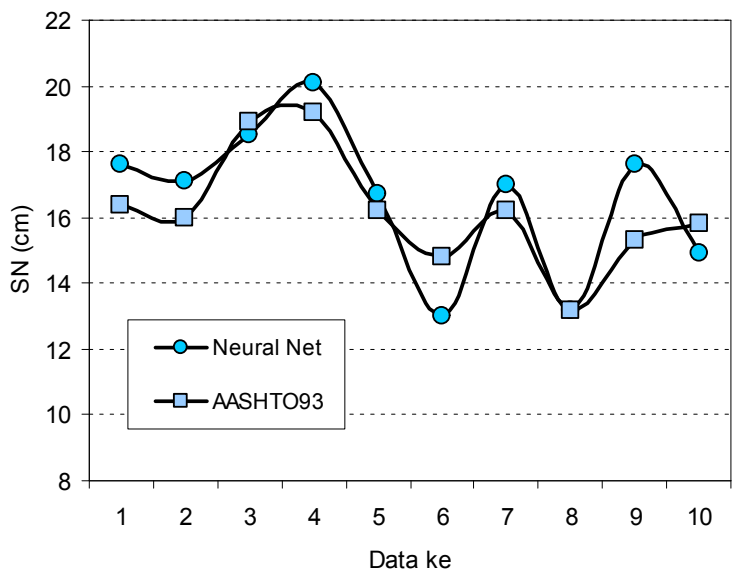

Figure 6. SNeff at location Padalarang-Purwakarta

The result of location Padalarang-Purwakarta using 2 methods i.e. AASHTO'93 and Neural Network method give a really good trend. Individually the different of each method is maximum $15 \%$ (at data $9^{\text {th }}$ ) and minimum $0 \%$. By averaging error for the link tested the error obtained is a really small that is $2.3 \%$ as written in Table 2 .

From Figures 6 and 7 it can be said that the trend of the results by neural network method is still following the trend of AASHTO'93. In the location Jatibarang all of the results of AASHTO'93 is a bit higher than that of neural network, the results of Jatibarang there are some results of AASHTO'93 that is lower than that of neural network method.

In general for location Padalarang-Purwakarta, the SNeff of AAHTO'93 is only a bit higher than that of neural network method.

The last location observed is Jl. Sukarno-Hatta, Bandung. The results of both calculation is given in Table 3 and Figure 7 respectively. Just likes the two locations before, the trend of SNeff calculated for this location is the same which the SNeff of neural network method is lower than that of AASHTO'93. For average the difference of these data is about $15.4 \%$.
Table 3. Results of Jl. Sukarno-Hatta, Bandung

\begin{tabular}{|c|c|c|c|}
\hline \multirow{2}{*}{ Data ke } & \multicolumn{2}{|c|}{ SN (cm) } & \multirow{2}{*}{$\%$ error } \\
\cline { 2 - 3 } & AASHTO'93 & Neural Net & \\
\hline 1 & 12.8 & 10.9 & 17.4 \\
\hline 2 & 13.6 & 11.4 & 19.3 \\
\hline 3 & 12.5 & 10.5 & 19.0 \\
\hline 4 & 13.0 & 11.6 & 12.1 \\
\hline 5 & 13.3 & 11.2 & 18.8 \\
\hline 6 & 11.9 & 10.1 & 17.8 \\
\hline 7 & 12.8 & 11.0 & 16.4 \\
\hline 8 & 13.6 & 12.0 & 13.3 \\
\hline 9 & 14.4 & 12.4 & 16.1 \\
\hline 10 & 11.0 & 10.6 & 3.8 \\
\hline Rata-rata= & 12.9 & 11.2 & 15.4 \\
\hline
\end{tabular}

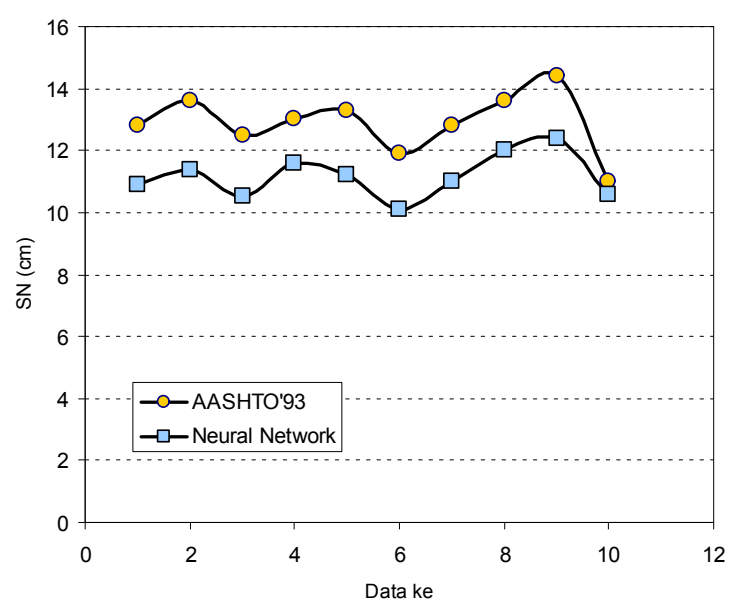

Figure 7. SNeff at location Sukarno-Hatta, Bandung

From explanation above the calculation of Sneff using neural network method is acceptable especially for the planning of road maintenance. Some advantages can be obtained by using this method i.e. relatively quick and economical because it does not the core drill or test pit and also it does not block the traffic flow especially in the urban areas.

\section{CONCLUSIONS}

There are some points can be drawn :

1. The use of neural network method can be an alternative one in analyzing and evaluation of existing pavement.

2. The neural network method has some advantages such as more economical, relatively quick and it does not block the traffic flow.

3. In general the Sneff of neural network method is a bit lower than that of AASHTO'93. 


\section{REFERENCES}

[1] AASHTO, 1993. AASHTO Guide for Design of Pavement Structure. American Asso-ciation of Stare Highways and Transportation Offi-cials, Washington DC.

[2] B. Xu, S. R. Ranjithan, and Y. R. Kim, Development Of Relationships Between FWD Deflections And Asphalt Pavement Layer Condition Indicators, Inter-national Journal of Compu-tational Intelligence Volume 3 Number 1, the TRB, Washington, D.C., 2001.

[3] Puspitaningrum, 2006. Pengantar Jaringan Syaraf Tiruan, Andi Offset, Yogyakarta

[4] Rojas R, 1996. Neural Networks A Systematic Introduction, Springer, Berlin

[5] Siegfried, 2009. Prediksi Tebal Lapisan Beraspal Meng-gunakan Data Lendutan FWD dan Metoda Neural Network Untuk Single Layer Perceptron. Jurnal Jalan dan Jembatan, Bandung. 